\title{
Küresel Bir Nükleer Reaktör İçin Ana ve Alternatif Bükülmedeki Değişimlerin Kritik Yarıçapa Etkisi
}

\section{The Influence of Changes in Principal and Alternate Buckling on the Critical Radius for a Spherical Nuclear Reactor}

\author{
Ali İhsan Göker ${ }^{1 *}$
}

Geliş / Received: 24/12/2020

Revize / Revised: 27/01/2021

Kabul / Accepted: 01/02/2021

ÖZ

Nükleer enerjinin ticari olarak kullanılması nükleer reaktörlerde gerçekleşen kontrollü fisyon reaksiyonu yoluyla mümkün olmaktadır. Fisyon reaksiyonun kontrollü gerçekleşmesi nötron sayısının sabit kalmasına bağlıdır. Buna kritiklik şartı denilmektedir. En basit yaklaşımda, fisyon reaksiyonunu tetikleyen nötronlar düşük enerjili termal nötronlar ve yüksek enerjili hızlı nötronlar olmak üzere enerjilerine göre iki ayrı gruba ayrılabilir. Buna iki gruplu nötron difüzyon teorisi adı verilir. Bu çalışmada, verilen bir reaktör kompozisyonu için kritikliği sağlayan reaktör yarıçapı iki gruplu kritiklik denklemini numerik olarak çözerek tespit edilmiştir. Bu yolla, küresel geometride ana ve alternatif bükülmedeki değişimlerin kritik reaktör yarıçapı üzerindeki etkileri detaylı bir şekilde irdelenmiştir.

Anahtar Kelimeler- Nükleer Enerji, Kritiklik, Nötron Difüzyonu, Fisyon

\begin{abstract}
Commercial utilization of the nuclear energy becomes possible through the controlled fission reaction that occurs within the nuclear reactors. Controlled realization of the fission reaction depends on the neutron number staying constant. This is called criticality condition. In the simplest approximation, the neutrons that trigger the fission reaction can be separated into two groups as low energy thermal neutrons and high energy fast neutrons. This is named two group neutron diffusion theory. In this work, the reactor radius that satisfies the criticality for a given reactor composition has been determined by solving the two group criticality equation numerically. In this manner, the effects of changes in principal and alternate buckling on critical reactor radius have been elucidated in a detailed way.
\end{abstract}

Keywords- Nuclear Energy, Criticality, Neutron Diffusion, Fission

${ }^{1 *}$ Sorumlu yazar iletișim: agoker@gmail.com(https://orcid.org/0000-0001-8645-4617)

Fizik Bölümü, Bilecik Şeyh Edebali Üniversitesi, Fen Edebiyat Fakültesi, 11210, Bilecik, Türkiye 


\section{GíRiş}

Küresel ısınmanın giderek kendini hissettirmesinden dolayı, enerji ve diğer endüstriyel faaliyetler sonucu oluşan $\mathrm{CO}_{2}$ emisyonlarının azaltılması gereği son yıllarda giderek önem kazanmaktadır. [1,2] $\mathrm{Bu}$ doğrultuda, $\mathrm{CO}_{2}$ yayılımının çok fazla olduğu fosil yakıtlar yerine yenilenebilir enerji kaynaklarının kullanılması uygulamaya konulmuştur. Fakat yenilenebilir enerji kaynaklarının düşük verim ve kesintili enerji üretim yapısından dolayı nükleer enerji kesintisiz ve yüksek verim ile enerji üretimine imkan tanımasından dolayı güçlü bir alternatif olarak kendini göstermektedir. Çernobil ve Fukushima benzeri sızıntı vakalarının kamuoyunda oluşturduğu tedirginlik nükleer enerjiye olan ilgiyi azaltmaktadır. [3,4] Nükleer enerjinin yaygın olarak kullanıma girebilmesi için güvenlik sorunlarının hassasiyetle çözülmesi hayati önem taşımaktadır. Bu bakımdan da reaktörde sızıntıya yol açabilecek ana etmen olan nötron dağılımının doğru olarak bilinmesi ve tasarımın o doğrultuda yapılması gerekmektedir.

Bir nükleer reaktörün gerçeğe uygun tasarlanabilmesi için, fisyon reaksiyonuna yol açan nötronların çekirdek içindeki dağılımlarının doğru ve hassas bir şekilde tahmin edilmesi önem arzetmektedir. Şanssız bir şekilde, nötron dağılımını kesin olarak belirlemek genelde oldukça zor bir problemdir çünkü reaktör içindeki nötronlar tekrarlanan nükleer çarpışmalardan dolayı oldukça karmaşık yollar takip ederler. Buna rağmen, bu çarpışmaların toplamda etkisi nötronların reaktör ortamında difüzyona maruz kalması olarak kabul edilebilir. Bu, bir gazın bir diğeri içinde yayılmasıyla analogdur. Dolayısıyla, nötron dağılımının yaklaşık değeri difüzyon denklemini çözerek elde edilebilir. Bu denklem, moleküler taşınma gibi mühendisliğin diğer dallarında kullanılan difüzyon denkleminin aynısıdır.

Fisyonu tetikleyen nötronlar farklı enerji değerlerinde oldukları için, bu enerjiler aralıklara ayrılarak çok gruplu nötron difüzyon denklemleri ortaya çıkmıştır. Yüksek enerjili bir nötron, nükleer çekirdekle yaptığ inelastik çarpışma sonucu enerjisinin bir kısmını kaybederek bir alt gruba düşmekte ve reaksiyon bu şekilde devam etmektedir. Dolayısıyla farklı gruplardaki nötron akıları birbiriyle eşleşmiş durumdadır. Çok hassas hesaplamalarda, grup sayısı çok fazladır. Nötron difüzyon denklemlerinin çözümü için genelleştirilmiş Pade ve kesikli çarpım yaklaşımı [5], adaptif matris formasyon metodu [6], ilerleyici polinom yaklaşımı [7] ve sınır elemanı-tepki matrisi metodu [8] gibi değişik teknikler geliştirilmiştir. Bu çalışmada, nötronları oda sıcaklığında olanlar ve onun üstünde kalan enerjiye sahip geri kalanların tamamı olmak üzere iki farklı gruba ayırarak, verilen bir reaktör kompozisyonu için kritik reaktör boyutlarını iki gruplu nötron difüzyon denklemini numerik olarak çözerek tespit ettik.

\section{MATERYAL VE METOT}

$R$ yarıçapına sahip küresel geometriye sahip bir nükleer reaktör çekirdeğindeki nötron akısı $\phi=n u$ ile ifade edilebilir. Burada $n$ nötron yoğunluğu $u$ ise nötron hızıdır. Reaktörün çekirdeğinin içinde nötronlar

$$
J_{r}=-D \frac{d \phi}{d r}
$$

şeklinde verilen Fick kanununa uygun şekilde difüzyona yani yayılmaya tabidirler. Burada $D$ difüzyon katsayısıdır. Fick kanununu süreklilik denkleminde yerine yazarsak denge denklemlerine ulaşırız. Bu çalışmada nötronları termal ve hızlı nötronlar olarak 2 gruba ayıracağı. Termal nötronlar enerjileri $0.25 \mathrm{eV}$ civarında olan nötronlara karşılık gelirken, bunun üzerinde enerjiye sahip tüm nötronları hızlı nötronlar olarak kategorize edeceğiz. Hızlı grup için denge denklemi

$$
D_{1} \nabla^{2} \phi_{1}-\Sigma_{1 s} \phi_{1}-\Sigma_{1 a} \phi_{1}+v \Sigma_{1 f} \phi_{1}+v \Sigma_{2 f} \phi_{2}=0
$$

şeklinde yazılabilir. Buradaki terimler sırasıyla kaçak, saçılma yoluyla alt gruba indirgeme, emilme, hızlı fisyon ve termal fizyona karşılık gelir. $\phi_{1}$ hızlınötronakısı, $\phi_{2}$ ise termal nötron akısınakarşılıkgelirken $v$ fisyonreaksiyonubaşına oluşan nötron sayısını göstermektedir. $\sum$ değerleriisebusüreçler için makroskopik kesit alanlardır. Termal nötronlar için denge denklemi ise

$$
D_{2} \nabla^{2} \phi_{2}-\Sigma_{2 a} \phi_{2}+\Sigma_{1 s} \phi_{1}=0
$$


olarak yazılır. Buradaki terimler de yine kaçak, emilme ve hızlı gruptan elastik olmayan çarpışma ile aşağı inen nötronlara karşılık gelmektedir. Burada dikkat çekmek istediğimiz husus, termal grupta fisyon kaynağı olmayıp tek nötron kaynağının hızlı gruptan aşağı inen nötronlar olmasıdır. Reflektör içermeyen bir reaktörde, termal nötron akısının hızlınötronakısınaoranı

$$
\frac{\phi_{2}}{\phi_{1}}=\frac{\Sigma_{1 s}}{D_{2} B^{2}+\Sigma_{2 a}}
$$

ile verilen bir sabittir.

$R$ yarıçapına sahip bir nükleer reaktör çekirdeği ve onun etrafını saran $T$ kalınlığındaki bir yansıtıcı tabakası arasındaki sınırda nötron akı ve akımının sürekliliğini sağlayan denklemler $[9,10]$

$$
\begin{aligned}
& \phi_{1 c}=\phi_{1 r} \\
& \phi_{2 c}=\phi_{2 r} \\
& -D_{1 c} \nabla \phi_{1 c}=-D_{1 r} \nabla \phi_{1 r} \\
& -D_{2 c} \nabla \phi_{2 c}=-D_{2 r} \nabla \phi_{2 r}
\end{aligned}
$$

ileverilir. Burada $D_{1 r, 2 r}$ hızlıvetermal nötronların çekirdektekidifüzyonkatsayılarını, $D_{1 c, 2 c}$ isehızlıvetermal nötronların yansıtıcıdaki difüzyon katsayılarını gösterir. Çekirdekteki hızlı ve termal nötron akıları ise sırasıyla

$$
\begin{aligned}
& \phi_{1 c}=A \frac{\sin \mu r}{r}+C \frac{\sinh v r}{r}=A X+C Y \\
& \phi_{2 c}=A S_{1} \frac{\sin \mu r}{r}+C S_{2} \frac{\sinh v r}{r}=A S_{1} X+C S_{2} Y
\end{aligned}
$$

denklemleriyleverilir. $\mathrm{Bu}$ denklemlerde $\mu^{2}$ ve $v^{2}$ sırasıylaana bükülme ve alternatif bükülme olarakadlandırılmaktadırve $v^{2}=\mu^{2}+b$ ilişkisiylebağlantılıdırlar. $b$ ise

$$
b=\frac{\Sigma_{1 s}+\Sigma_{1 a}-v \Sigma_{1 f}}{D_{1}}+\frac{\Sigma_{2 a}}{D_{2}}
$$

ile verilir ve daima pozitiftir. Bundan dolayı her zaman $v \geq \mu$ şartısağlanır.

Yansıtıcıdaki hızlı ve termal nötron akıları ise

$$
\begin{aligned}
& \phi_{1 r}=F \frac{\sinh \left(\frac{R+T-r}{L_{1 r}}\right)}{r}=F Z_{1} \\
& \phi_{2 r}=G \frac{\sinh \left(\frac{R+T-r}{L_{2 r}}\right)}{r}+S_{3} F \frac{\sinh \left(\frac{R+T-r}{L_{1 r}}\right)}{r}=G Z_{2}+S_{3} F Z_{1}
\end{aligned}
$$


şeklinde yazılabilir. Bu denklemlerde, $L_{1 r, 2 r}$ hızlıvetermalnötronların yansıtıcıdaki difüzyon uzunluğudur. $S_{1}$, $S_{2}$ ve $S_{3}$ iseeşleşme katsayılarıdır. Bu ifadeleri 4. denklemde yerine koyupmatrisşeklindeyazarsak

$$
\left(\begin{array}{cccc}
X & Y & -Z_{1} & 0 \\
S_{1} X & S_{2} Y & -S_{3} Z_{1} & -Z_{2} \\
D_{1 c} X^{\prime} & D_{1 c} Y^{\prime} & -D_{1 r} Z_{1}{ }^{\prime} & 0 \\
D_{2 c} S_{1} X^{\prime} & D_{2 c} S_{2} Y^{\prime} & -D_{2 r} S_{3} Z_{1}^{\prime} & -D_{2 r} Z_{2}^{\prime}
\end{array}\right)\left(\begin{array}{c}
A \\
C \\
F \\
G
\end{array}\right)=0
$$

ile karşı karşıya geliriz. Burada $X^{\prime}, Y^{\prime}, Z^{\prime}{ }_{1}, Z_{2}^{\prime}$ birinci türevi temsil etmektedir. Bu, 4 bilinmeyenli $(A, C, F$ ve $G) 4$ lineer cebirsel denklemdir. Burada sıradan çözüm $(A=C=F=G=0)$ haricinde bir çözüm eldeetmenintekyolu

$$
\left|\begin{array}{cccc}
X & Y & -Z_{1} & 0 \\
S_{1} X & S_{2} Y & -S_{3} Z_{1} & -Z_{2} \\
D_{1 c} X^{\prime} & D_{1 c} Y^{\prime} & -D_{1 r} Z_{1}{ }^{\prime} & 0 \\
D_{2 c} S_{1} X^{\prime} & D_{2 c} S_{2} Y^{\prime} & -D_{2 r} S_{3} Z_{1}^{\prime} & -D_{2 r} Z_{2}{ }^{\prime}
\end{array}\right|=0
$$

şartının sağlanmasıdır. Bu ifadede ilk sütunu $X$, ikinciyi $Y$, üçüncüyü $Z_{1}$ ve dördüncüyü $Z_{2}$ ile böldükten sonra üçüncü satırı $D_{l c}$ ve dördüncü satırı $D_{2 c}$ ile bölmek determinantın değerini değiştirmez. Bu düzenlemeninsonunda

$$
\left|\begin{array}{cccc}
1 & 1 & -1 & 0 \\
S_{1} & S_{2} & -S_{3} & -1 \\
\alpha & \beta & -\rho_{1} \gamma & 0 \\
S_{1} \alpha & S_{2} \beta & -\rho_{2} S_{3} \gamma & -\rho_{2} \delta
\end{array}\right|=0
$$

ifadesini elde ederiz. Burada $\alpha=\frac{X^{\prime}}{X}, \beta=\frac{Y^{\prime}}{Y}, \gamma=\frac{Z_{1}^{\prime}}{Z_{1}}, \delta=\frac{Z_{2}^{\prime}}{Z_{2}}, \rho_{1}=\frac{D_{1 r}}{D_{1 c}}$ ve $\rho_{2}=\frac{D_{2 r}}{D_{2 c}}$ olarakverilir.

9. denklemdeki determinantı açıp cebirsel hale getirirsek

$$
\alpha=\frac{\rho_{2} \delta C_{1}+\rho_{1} \gamma C_{2}+\beta C_{3}}{C_{1}+C_{2}+C_{3}}
$$

eşitliğini elde ederiz. Bu denklemde

$$
\begin{aligned}
& C_{1}=S_{1}\left(\rho_{1} \gamma-\beta\right) \\
& C_{2}=S_{2}\left(\beta-\rho_{2} \delta\right) \\
& C_{3}=S_{3} \rho_{2}(\delta-\gamma)
\end{aligned}
$$

ile verilir. Öte yandan, $X^{\prime}, Y^{\prime}, Z^{\prime}, Z_{2}^{\prime}$ açıkolarak

$$
X^{\prime}(r)=\frac{\mu \cos \mu r}{r}-\frac{\sin \mu r}{r^{2}}
$$




$$
\begin{aligned}
& Y^{\prime}(r)=\frac{v \cosh v r}{r}-\frac{\sinh v r}{r^{2}} \\
& Z_{1}^{\prime}(r)=\frac{-\frac{1}{L_{1 r}} \cosh \frac{R+T-r}{L_{1 r}}}{r}-\frac{\sinh \frac{R+T-r}{L_{1 r}}}{r^{2}} \\
& Z_{2}^{\prime}(r)=\frac{-\frac{1}{L_{2 r}} \cosh \frac{R+T-r}{L_{2 r}}}{r}-\frac{\sinh \frac{R+T-r}{L_{2 r}}}{r^{2}}
\end{aligned}
$$

şeklinde belirtilebilir. Bizim hesaplamamıza referans teşkil eden denklem 10'dur. Bu makalede hedefimiz, verilen bir reaktör kompozisyonu için kritik yarıçap değerlerini hesaplamaktır. Bu amaç doğrultusunda takip ettiğimiz metot 10. denklemin sağ ve sol tarafindaki ifadelerin r'nin fonksiyonu olarak grafiğini çizmektir. Reaktör çekirdeğinin içinde bulunan bölgedeki kesişim noktaları bize kritik yarıçapı verecektir.

\section{BULGULAR VE TARTIŞMA}

Kritik reaktör yarıçapını tespit edebilmek için $R=5 \mathrm{~m}, T=0.5 \mathrm{~m}$ olarak vekatsayıları da $\rho_{1}=1, \rho_{2}=1, S_{1}$ $=1, S_{2}=2, S_{3}=3$ şeklindesabitleyereksayısal hesaplamaları gerçekleştirdik. Sayısal hesaplamalarımız yukarıda detaylı bir şekilde anlatıldığı üzere 7. denklemin sağ ve sol taraflarının $r$ 'nin fonksiyonu olarak grafiğinin çizilmesiyle gerçekleştirilmiş̧ir. Bu hesaplamaların ilk adımında difüzyon uzunluklarını $L_{l r}=2 \mathrm{~m}$ ve $L_{2 r}=1 \mathrm{~m}$ alıp, $\mu$ ve $v$ değerlerinideğiştirerek iki eğrinin kesişim noktalarının yani kritik yarıçapların nasıl davrandığını inceledik. Dikkat çekmek istediğimiz birdiğerhusus $v^{2}=\mu^{2}+b$ olduğuiçinhesaplamalarımızdaseçtiğimiz $\mu$ ve $v$ parametreleri her zaman $v \geq \mu$ şartınısağlamaktadır. Elde ettiğimiz sonuçlar şekil 1, şekil 2, şekil 3., şekil 4 ve şekil 5 'te gösterilmiştir. Bu şekillerin hepsinde $y$ ekseninin birimi $\mathrm{m}^{-1}$ 'dir.

Şekil 1'de reaktörün içinde kritiklik şartını sağlayan 3 yarıçapvarken, $v$ sabitken $\mu$ azaldıkçakritiklikşartını sağlayan yarıçap sayısının giderek azaldığı görülmektedir. Nitekim, şekil 2'de kritiklik şartııı sağlayan yarıçap sayısı 3'e, şekil 3'de ise 2'ye düşmektedir. Bu hesaplamalarsırasında $v$ sabittutulmuştur. Öteyandan $\mu$ sabitken, $v$ nünazaltılması kritik yarıçap sayısını etkilemezken, kritik yarıçap değerlerini değiştirmektedir.

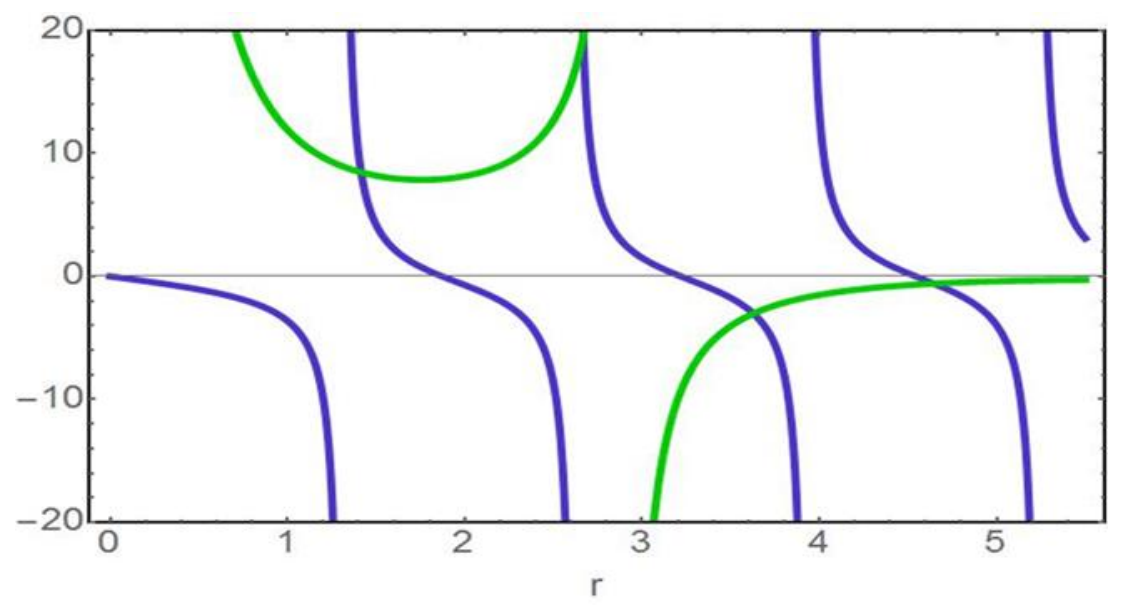

Şekil 1. $\mu=2.4$ ve $v=2.4$ için 7. Denklemin sağ (yeşil eğri) ve sol taraflarının (mavi eğri) $r$ 'nin fonksiyonu olarak grafiği 


\begin{tabular}{|c|c|c|}
\hline & $\begin{array}{l}\text { BŞEÜ Fen Bilimleri Dergisi } \\
8(1), 116-124,2021\end{array}$ & $\begin{array}{r}\text { BSEU Journal of Science } \\
\text { https://doi.org/10.35193/bseufbd.846417 }\end{array}$ \\
\hline $\begin{array}{l}\text { BILECE SEYY EDEBALI } \\
\text { UNIVERSITES| }\end{array}$ & & 2458-7575 (https://dergipark.org.tr/tr/pub/bseufbd) \\
\hline
\end{tabular}

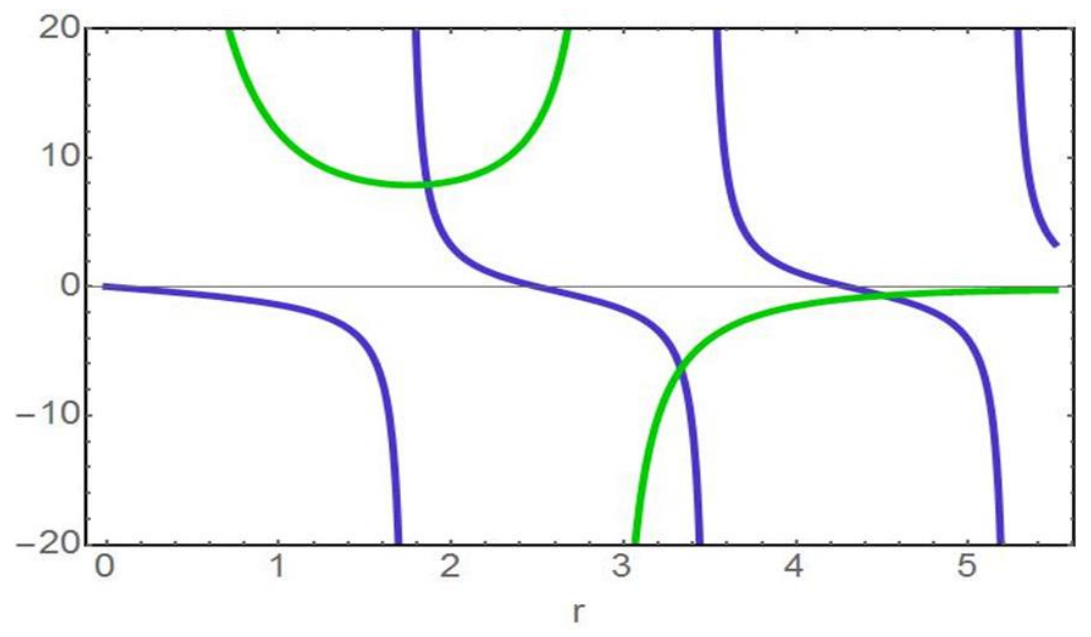

Şekil 2. $\mu=1.8$ ve $v=2.4$ için 7. denklemin sağ(yeşil eğri) ve sol taraflarının (mavi eğri) $r$ 'nin fonksiyonu olarak grafiği.

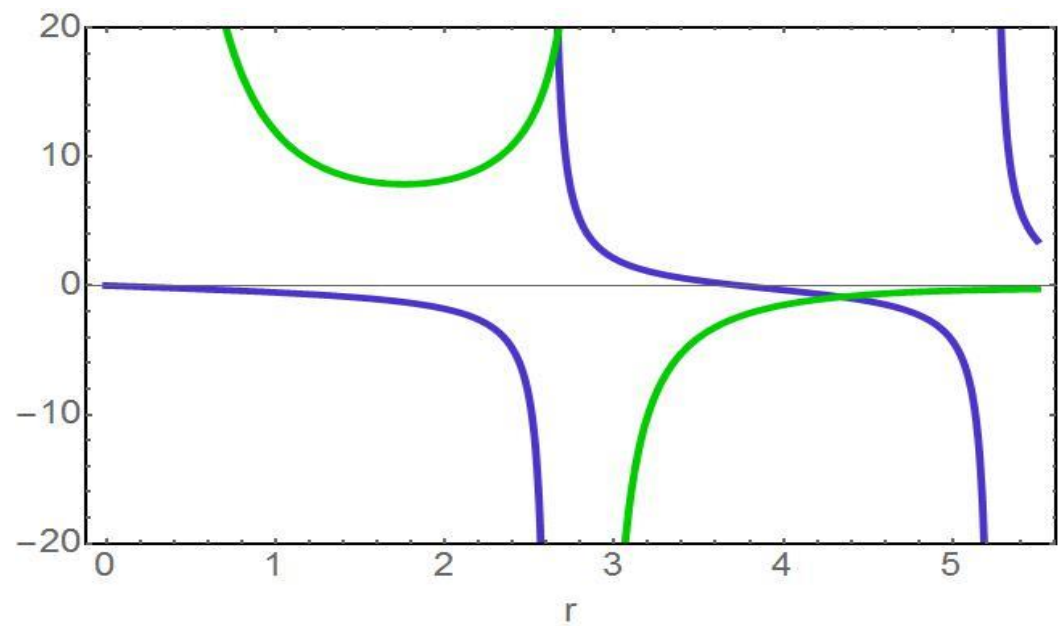

Şekil 3. $\mu=1.2$ ve $\nu=2.4$ için 7. denklemin sağ (yeşil eğri) ve sol taraflarının (mavi eğri) r'nin fonksiyonu olarak grafiği

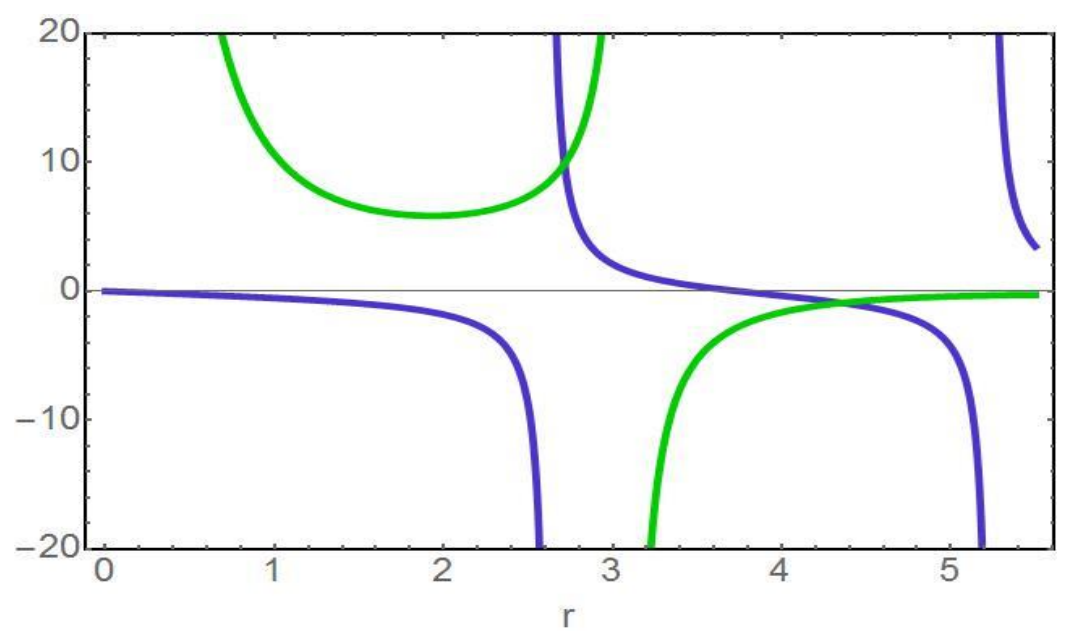

Şekil 4. $\mu=1.2$ ve $v=1.8$ için 7 . denklemin sağ (yeşil eğri) ve sol taraflarının (mavi eğri) $r$ 'nin fonksiyonu olarak grafiği. 


\begin{tabular}{|c|c|c|}
\hline & $\begin{array}{l}\text { BŞEÜ Fen Bilimleri Dergisi } \\
8(1), 116-124,2021\end{array}$ & $\begin{array}{r}\text { BSEU Journal of Science } \\
\text { https://doi.org/10.35193/bseufbd.846417 }\end{array}$ \\
\hline & & 2458-7575 (https://dergipark.org.tr/tr/pub/bseufbd) \\
\hline
\end{tabular}

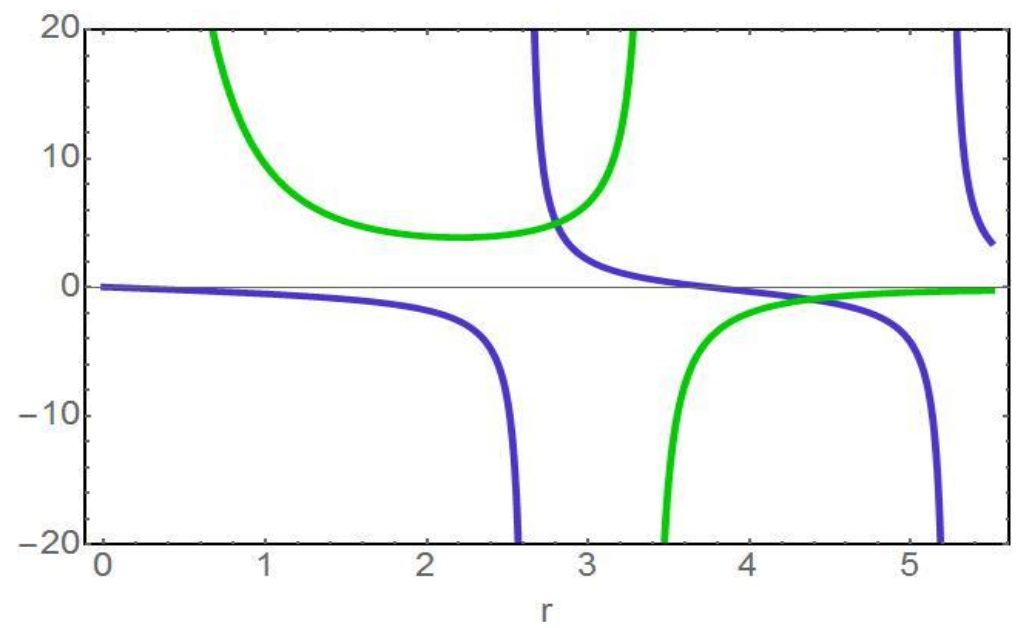

Şekil 5. $\mu=1.2$ ve $\nu=1.2$ için 7. denklemin sağ (yeşil eğri) ve sol taraflarının (mavi eğri) $r$ 'nin fonksiyonu olarak grafiği.

$\mathrm{Bu}$ sonuçların genelliğini tespit etmek için hesaplamalarımızı $L_{1 r}=2 \mathrm{~m}$ ve $L_{2 r}=0.5 \mathrm{~m}$ için aynı hesaplamaları tekrarladık. Sonuçlar şekil 6, şekil 7, şekil 8., şekil 9 ve şekil 10'da gösterilmiştir. Şekil 6'da yine şekil 1'de olduğu gibi reaktör içinde kritiklik şartını sağlayan 4 yarıçapvarken, $v$ sabitken $\mu$ azaldıkça yine kritiklik şartını sağlayan yarıçap sayısı şekil 7'de önce 3'e sonra şekil 8'de 2'ye düşmektedir. Dolayısıyla genel davranış aynıdır. Son olarak, $\mu$ sabitken $v$ 'nün azalması daha önce olduğu gibi kritik yarıçap sayısını etkilemezken sadece değerlerini değiştirmektedir. Bu da şekil 9 ve şekil 10'da görülmektedir. Her iki durumda da kritik yarıçap sayısı değişmeyip 2 olarak kalmıştır. Dikkat çekmek istediğimiz son nokta reaktör çekirdek yarıçapı $R=5 \mathrm{~m}$ alındığ 1 için bu çalışmada sadece çekirdek içinde kalan matematiksel çözümleri tespit ettik. Reaktör çekirdeği dışında kalan matematiksel çözümler fiziksel olmadığı için göz ardı edilmiştir.

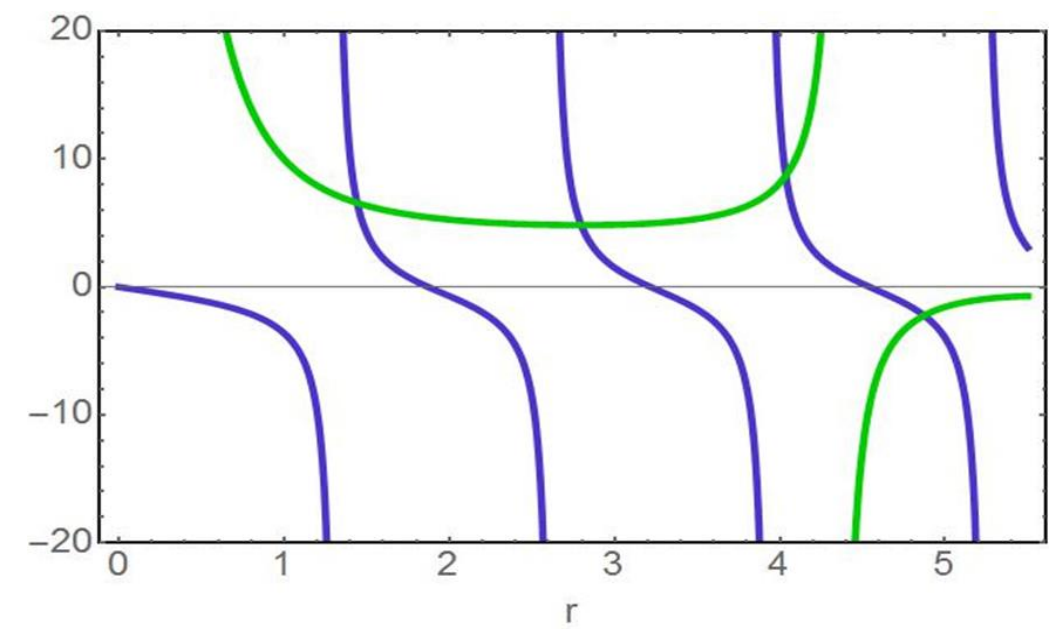

Şekil 6. $\mu=2.4$ ve $v=2.4$ için 7. denklemin sağ (yeşil eğri) ve sol (mavi eğri)taraflarının $r$ 'nin fonksiyonu olarak grafiği. 


\begin{tabular}{|c|c|c|}
\hline & $\begin{array}{l}\text { BŞEÜ Fen Bilimleri Dergisi } \\
8(1), 116-124,2021\end{array}$ & $\begin{array}{r}\text { BSEU Journal of Science } \\
\text { https://doi.org/10.35193/bseufbd.846417 }\end{array}$ \\
\hline $\begin{array}{l}\text { BILECIK SEYY EDEBALL } \\
\text { ONIVERSITESI }\end{array}$ & & 2458-7575 (https://dergipark.org.tr/tr/pub/bseufbd) \\
\hline
\end{tabular}

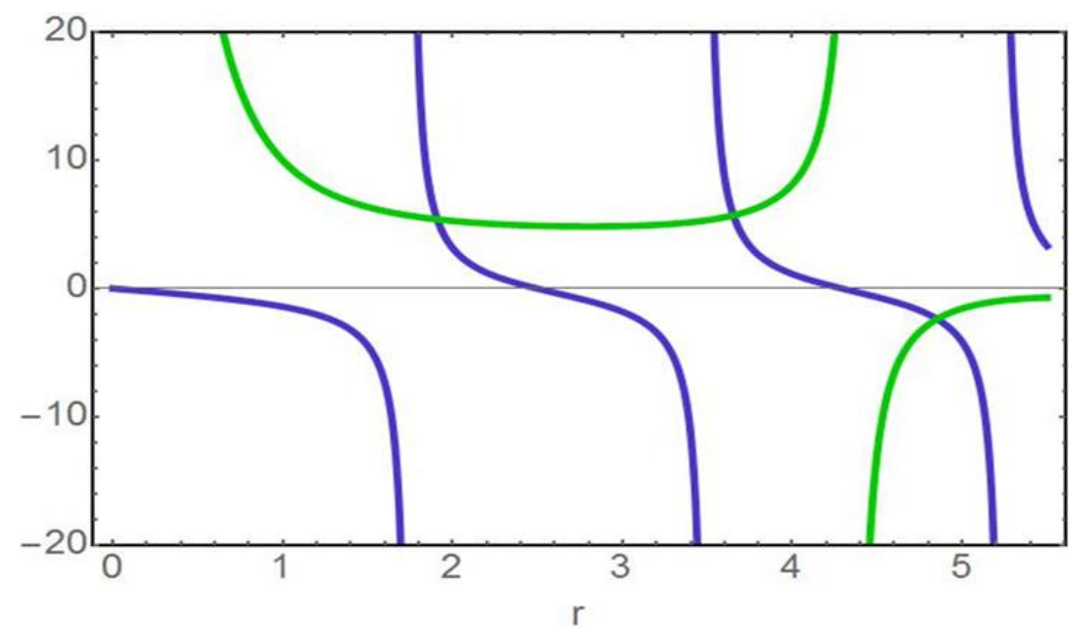

Şekil 7. $\mu=1.8$ ve $v=2.4$ için 7. denklemin sağ (yeşil eğri) ve sol (mavi eğri)taraflarının $r$ 'nin fonksiyonu olarak grafiği.

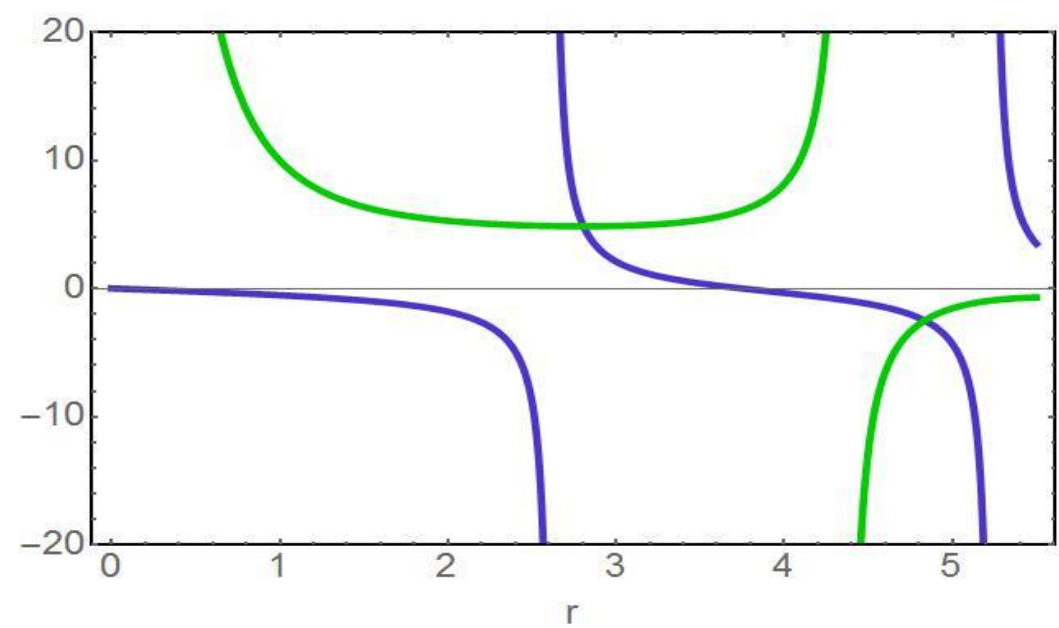

Şekil 8. $\mu=1.2$ ve $v=2.4$ için 7. denklemin sağ (yeşil eğri) ve sol taraflarının (mavi eğri) $r$ 'nin fonksiyonu olarak grafiği

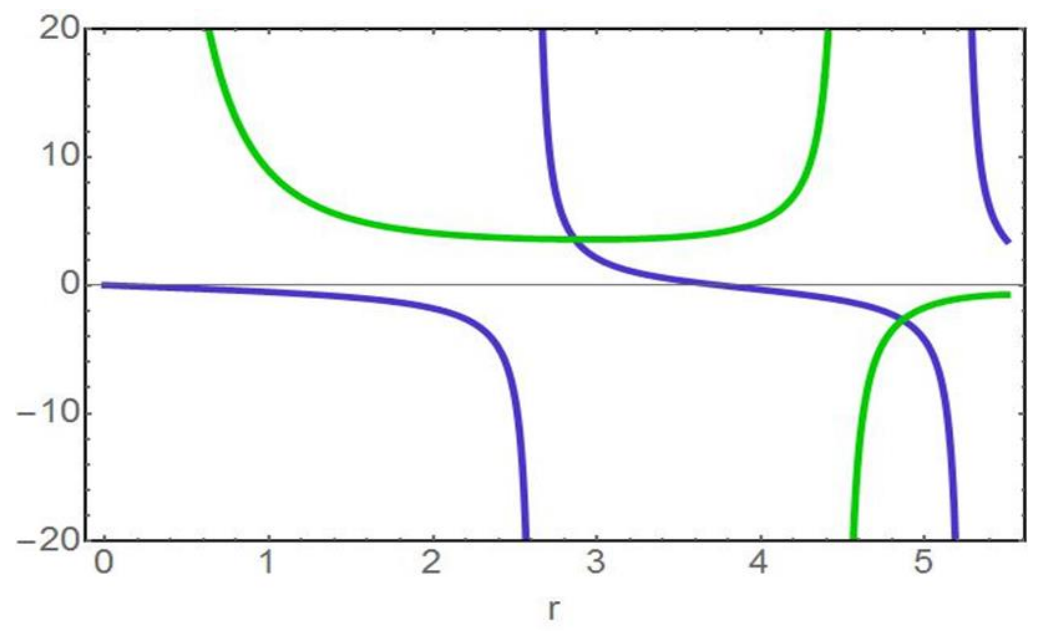

Şekil 9. $\mu=1.2$ ve $v=1.8$ için 7. denklemin sağ (yeşil eğri) ve sol taraflarının (mavi eğri) $r$ 'nin fonksiyonu olarak grafiği 


\begin{tabular}{|c|c|c|}
\hline & $\begin{array}{l}\text { BŞEÜ Fen Bilimleri Dergisi } \\
8(1), 116-124,2021\end{array}$ & $\begin{array}{r}\text { BSEU Journal of Science } \\
\text { https://doi.org/10.35193/bseufbd.846417 }\end{array}$ \\
\hline & & 2458-7575 (https://dergipark.org.tr/tr/pub/bseufbd) \\
\hline
\end{tabular}

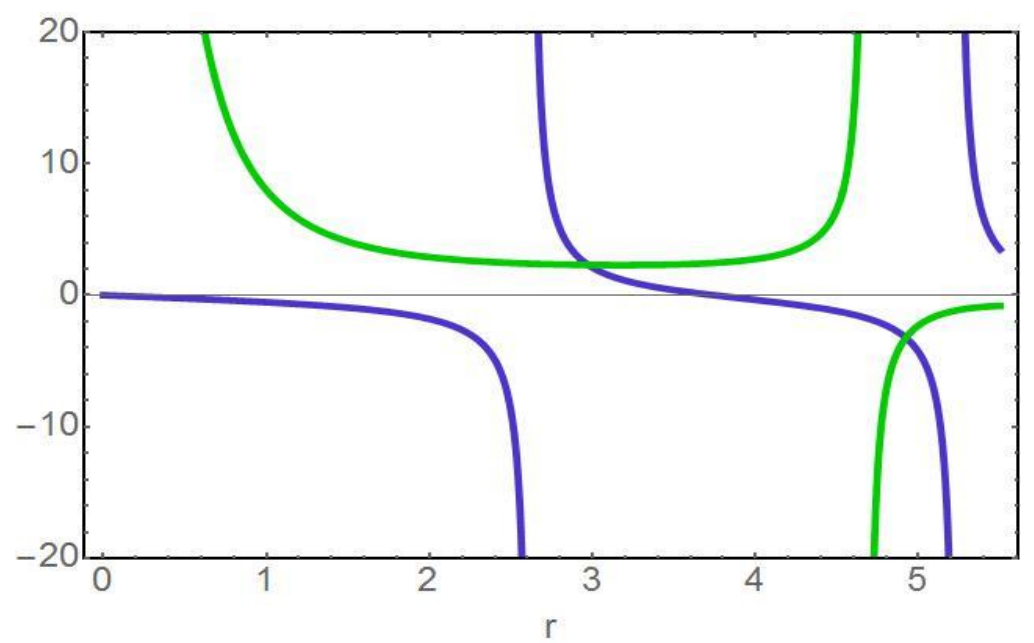

Şekil 10. $\mu=1.2$ ve $v=1.2$ için 7. denklemin sağ (yeşil eğri) ve sol taraflarının (mavi eğri) $r$ 'nin fonksiyonu olarak grafiği

\section{SONUÇLAR}

$\mathrm{Bu}$ çalışmayla bir nükleer reaktör çekirdeğinde meydana gelen fisyon reaksiyonunun güvenli olarak devam edebilmesi için zaruri olan kritiklik şartını sağlayan yarıçap değerlerini gerçek bir reaktöre olabildiğince yakın bir model olan iki gruplu nötron difüzyon teorisi yardımıyla hesaplamış olduk. Bu çalışmanın sonuçlarının kamuoyunda geniş yer alan reaktör güvenliği ve tasarımına ışık tutması dileklerimizi sunuyoruz. Ayrıca, gelecekte bu modeli daha fazla nötron grupları için gerçekleştirmeyi planladığımızı da belirtmek isteriz.

\section{KAYNAKLAR}

[1] Mitchell, C. (2016). Momentum is increasing towards a flexible electricity system based on renewables. Nature Energy, 1(2), 1-6.

[2] Meckling, J., Sterner, T., \& Wagner, G. (2017). Policy sequencing toward decarbonization. Nature Energy, 2(12), 918-922.

[3] Bunn, M., \& Heinonen, O. (2011). Preventing the next Fukushima. Science, 333(6049), 1580-1581.

[4] Dai, J., Li, S., Bi, J., \& Ma, Z. (2019). The health risk-benefit feasibility of nuclear power development. Journal of Cleaner Production, 224, 198-206.

[5] Aboanber, A. E., \& Nahla, A. A. (2006). Solution of two-dimensional space-time multigroup reactor kinetics equations by generalized Padé and cut-product approximations. Annals of Nuclear Energy, 33(3), 209-222.

[6] Aboanber, A. E., \& Nahla, A. A. (2007). Adaptive matrix formation (AMF) method of space-time multigroup reactor kinetics equations in multidimensional model. Annals of Nuclear Energy, 34(1-2), 103-119.

[7] Quintero-Leyva, B. (2010). The multi-group integro-differential equations of the neutron diffusion kinetics. Solutions with the progressive polynomial approximation in multi-slab geometry. Annals of Nuclear Energy, 37(5), 766-770.

[8] Maiani, M., \& Montagnini, B. (1999). A boundary element-response matrix method for the multigroup neutron diffusion equations. Annals of Nuclear Energy, 26(15), 1341-1369.

[9] Lewis, E. E., \& Miller, W. F. (1984). Computational methods of neutron transport.

[10] Marchuk, G. L., \& Lebedev, V. I. (1986). Numerical methods in the theory of neutron transport. 